\title{
Design and Analysis of ERP Integration for Pari Fish Leather Smes in Yogyakarta Using Web Service Technology
}

\author{
Reinhard Komansilan $^{1 *}$, Ade Iriani ${ }^{2}$ \\ 1,2 Magister of Information Systems, Faculty of Information Technology, Satya Wacana Christian \\ University, Salatiga, Central Java, Indonesia.
}

\begin{abstract}
Small and Medium Enterprises (SMEs) usually have limited markets and raw materials, so they cannot do mass production. The purpose of Enterprise Resource Planning (ERP) in Jogjakarta Pari Fish Leather SMEs is to maintain consumers and increase the effectiveness of using raw materials by integrating data on the production (factory) and marketing (shop / branch) sections using the SOAP method and REST web service. The results achieved are data integration between the marketing and manufacturing departments using SOAP and REST Web Service, as well as an ERP information and monitoring system that displays functions such as: sales charts, best-selling products, buyer's charts, and buyer's regional charts.
\end{abstract}

Keywords: Integration, SOAP, REST, Business process, ERP.

\section{Introduction}

The development of information technology is very fast forcing business people to adapt to technologies that can help improve business development and service to consumers [1]. The use of information technology, especially in the field of marketing business, has been widely applied and is the concern of business people. This also allows for better relationships between companies and consumers [2].

One of the roles of information technology is to provide a means of information processing and system integration, in order to be a good supporter of management. Integration between business processes and information systems must be carried out appropriately so that resources can be utilized optimally, so that they cannot separate information technology from the company's part [3].

To achieve the above objectives, it is necessary to develop an integrated system between parts of the company. One form of integrated system development in each part of the company is Enterprise Resource Planning (ERP). ERP is a series of business programs, usually consisting of modules to connect business units in a SME company such as marketing and manufacturing parts into an integrated system for data flow in the company [7].

Often in order to obtain large amounts of data, a company collaborates with other companies that serve consumers in similar market segments. Problems arise when each company has implemented an information system for product and consumer data for each company, so that it can hinder the integration process and even need to design new IT systems and infrastructure to meet the same needs of each company [5].

The purpose of this study is to integrate the business processes of the marketing and manufacturing sectors using the SOAP and REST web service methods. These methods allow companies not to need to redesign 
the entire IT infrastructure because each system can be integrated according to their needs with web services as a middleware for sending data and providing integration services on request $[5,6]$.

\section{Literature Review}

\subsection{Web Service}

Web service technology comes from the concept of SOA (Service Oriented Architecture) as a solution for business integration and information systems to be able to adapt to changes in the market. Web services provide standard integration that can overcome the complexity of information system architectures that have different business processes, architectures, programming languages, and platforms, but still must be maintained [8].

At present there are two types of web services, which are based on the SOAP principle and the REST principle. In SOAP-based web services, XML is used to define simple object access protocol (SOAP) is a protocol used by the data from the client to connect to the server. While RESTful web service is to build a web service in the form of representational state transfer (REST), that is, data from a client has a unique uniform resource identifier (URI) that can be connected to a server using simple web methods such as HTTP-GET, POST, and PUT.

In this case, we use both SOAP and REST integration principle to ensure dynamic implementation for multi-tenant and B2B business model. REST has no official standard because it is an architectural style. SOAP, on the other hand, has official standard because it is a protocol. These standards have possibility to be found different in each information system that has been implemented in stores, so the use of both principles can ensure the services can be used dynamically in every system found.

\subsection{ERP}

ERP is a type of business intelligence information system for manufacturing and service companies that serves to integrate and automate business processes. ERP systems help business processes to be more efficient by integrating business processes, such as marketing, manufacturing, logistics, accounting, and human resources [4].

In order to develop its information system, SMEs need to develop software and IT infrastructure to become more dynamic and up-to-date. The obstacles faced by SMEs in developing information systems according to Cruz-cunha (2010) are:

1. Not having enough resources and experts to rebuild the information system.

2. Difficulties faced by workers when a system change is made.

3. Difficulties in building a stable and reliable business process.

4. Cannot use complex software standards such as IEEE or ISO.

The solution is to use a third party, replacing a more modern and dynamic information system such as ERP. Employees and workers must also be disciplined in carrying out information system operations. Discipline in carrying out operational processes is a factor in the success of ERP implementation in SMEs [13].

\subsection{Previous Research}

Based on Sinha's research, et al. (2014), client applications for different companies can be integrated with REST-based web services on the cloud. The purpose of this research is the integration of applications in the cloud using web services as a middleware for sending data and providing IaaS (Integration as a Service) according to client requests. In this study, information systems in each part of the company will be 
integrated with similar web service methods, but adjusted according to the limits of the problem, objectives, and different business processes.

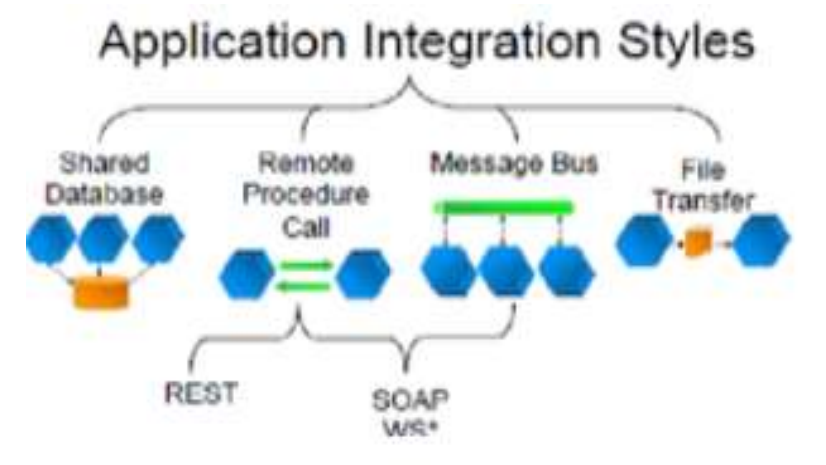

Figure 1 . Application integration model on cloud

Research Chang, et al (2014) in International Journal of Web Services Research, conducted measurements using four dimensions of service quality (ES-QUAL; efficiency, system availability, fulfillment, and privacy) provided by managers of online shopping sites to increase the level of customer satisfaction. Then the integration between the SIPA (simultaneous importance-performance analysis) method and the Kano analysis model is carried out to analyze the competitive strategy between managers of online shopping sites. The results of the integration analysis produce suggestions and potential management methods that need to be done by each company to increase customer satisfaction. In this study, the SOAP and REST web service methods are used in integrating data from the marketing and manufacturing departments to produce data analysis on ERP information systems sites that can be used by business managers in managing product and resource for competitive advantage and customer satisfaction.

In the study of Azevedo (2014), in his case study on the hospitality industry sector in Portugal, explained that the absence of information technology strategies such as ERP system application integration, especially in business process integration needs, would result in a lack of investment to be able to have a positive influence on business development such as improving services to consumers and business knowledge. Thus, the topic of ERP system integration in this study can be an information technology strategy that is used to help improve business knowledge in Pari Fish Leather SMEs in managing the information produced as a decision to increase production and service to consumers.

\section{Methodology}

Data collection carried out in this study are: interviews, observation, and literature. Interviews are conducted to obtain information such as sales data in the marketing and item data section in the manufacturer's parts. Observation is done to see the business processes that exist in the marketing and production department. Literature studies are conducted to compare previous research as a theoretical foundation and show the differences made in this study.

The data obtained are sales data for July and August 2014-2016, as well as inventory data up to 2017. Then observing the business processes carried out with analysis of the ongoing business activity. Identification of business processes carried out is business processes that are relevant to the scope of this research such as purchase data, marketing/sales data and production data. 

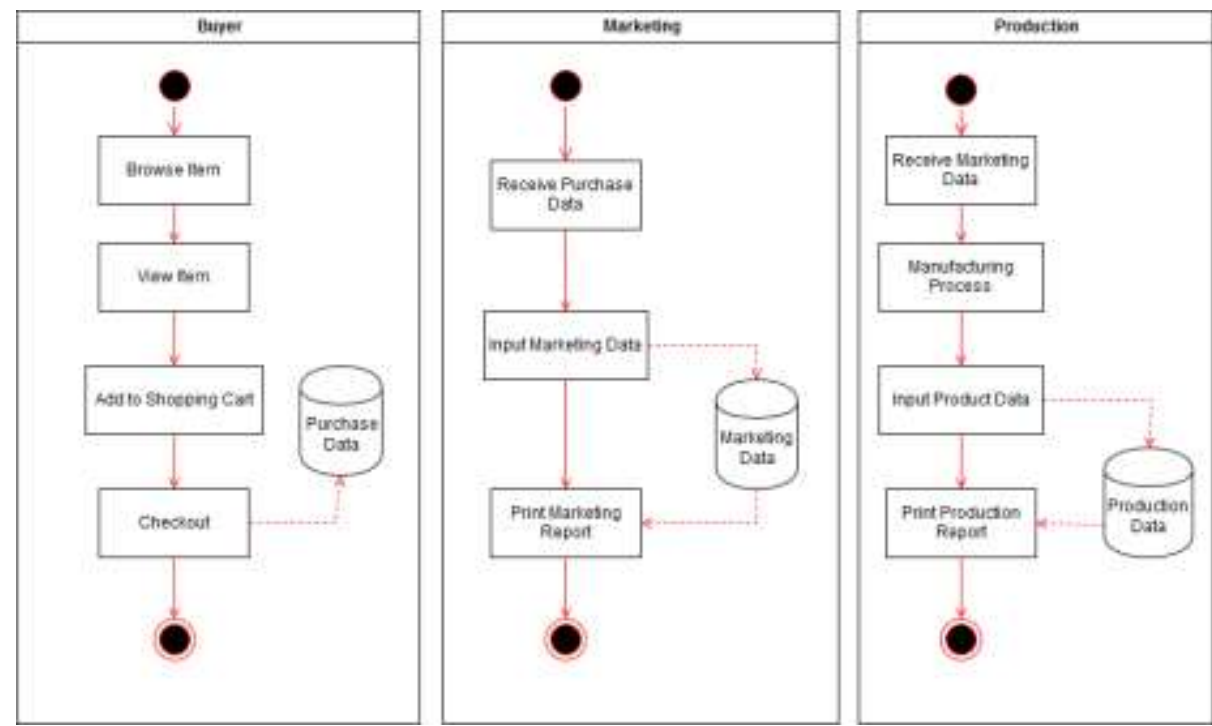

Figure 2. Business processes of the Pari Fish Leather SMEs traditional information system

The traditional business processes in each of the actors above will produce data that is not yet integrated, so business owners can only collect it manually and process the data for reporting purposes so that the owner can determine which production should be made to optimize the use of limited pari fish leather. That way, the traditional business processes cannot directly take part with the decision-making process by the business owner. This can cause more resource to be wasted before any decision can be taken.

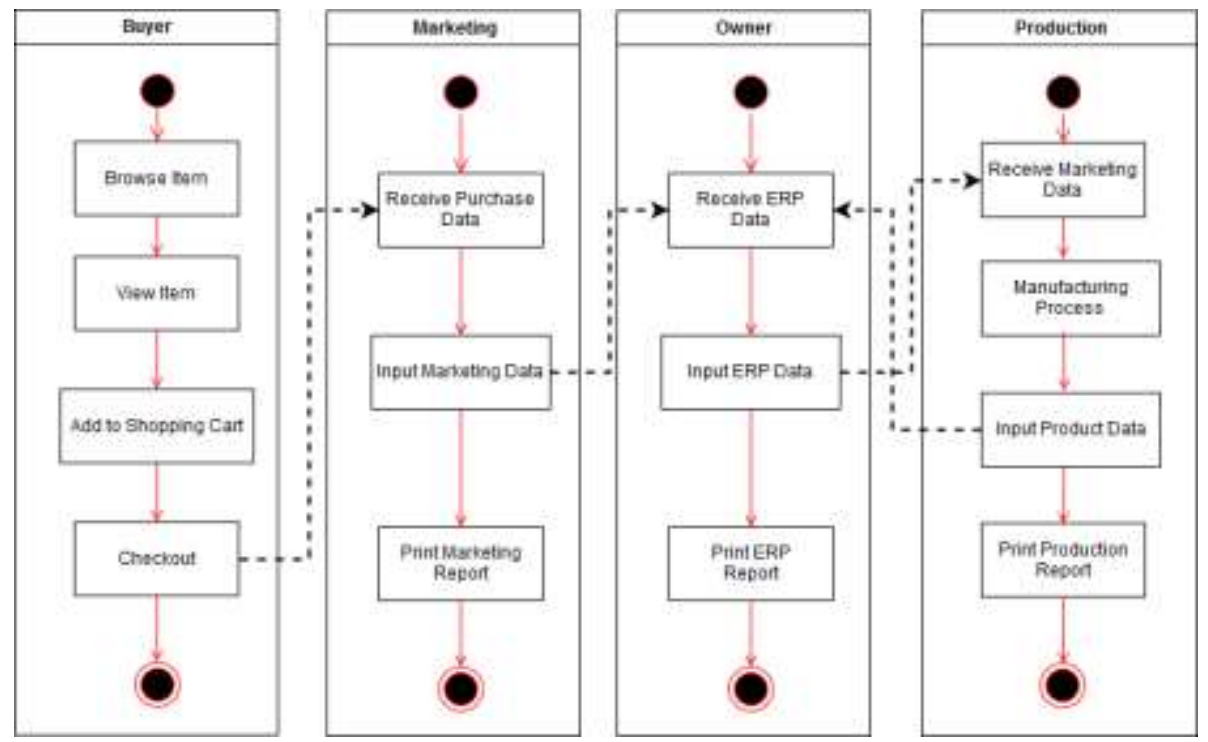

Figure 3. Proposed business processes of SMEs integrated ERP system

Based on the traditional processes above, we have analyzed and proposed an integrated business processes using web service orchestration model where a single centralized executable business process (the orchestrator) coordinates the interaction among different services [14]. Furthermore, these business processes will be the reference for creating client applications for each SOAP and REST web service server. This client application will be a part or module of an ERP system that functions as an interface for marketing and manufacturers in carrying out their business processes.

\subsection{Data Integration}

The activity in conducting data integration is to develop a data integration model to show the web service 
can solve the problems of software architecture differences in the ERP system in the marketing and manufacturing parts.

The first step in designing a data integration model is to conduct a needs analysis of the desired model then continue to database design and interaction processes between modules, after that we make the interface installed on web servers.

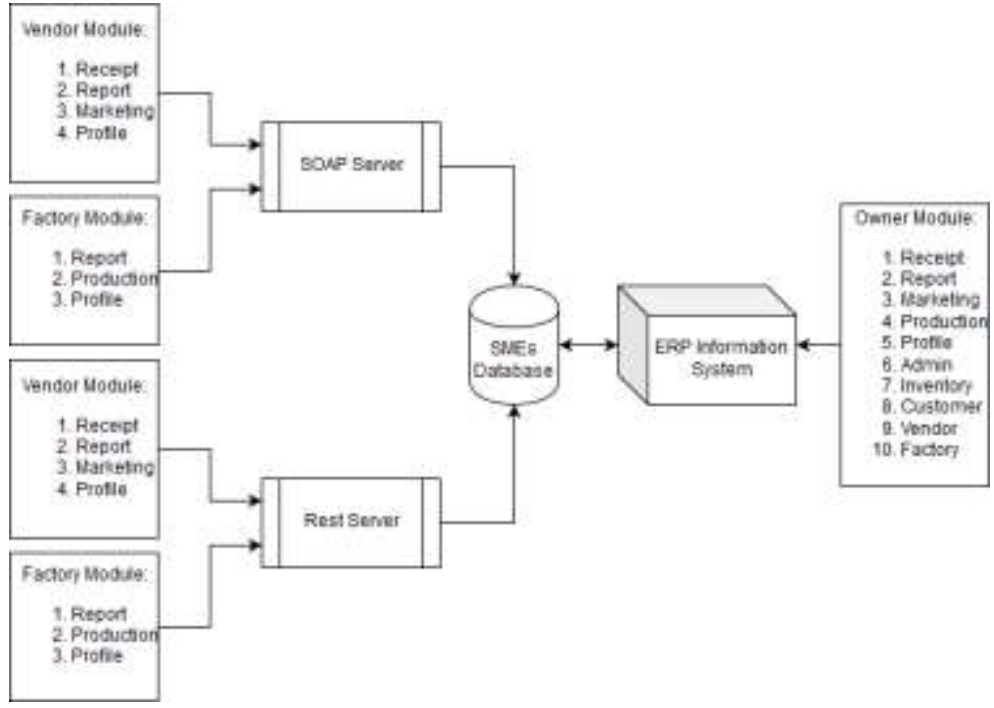

Figure 4. Data integration model

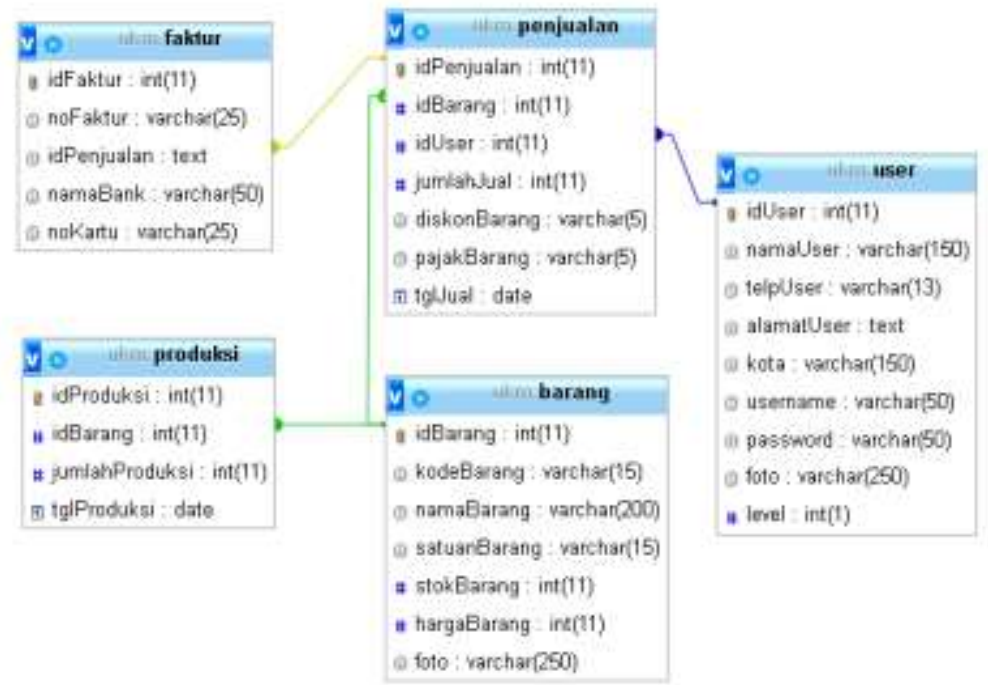

Figure 5. SMEs database for ERP systems

Every web server will have a web service that can be accessed by another application. Besides that, the web server too functions as a client that can execute web services owned by other web servers. The focus here is to implementing data exchange method (soap, rest) as data exchange media on two separate applications which are mounted on each web server platforms.

\subsection{ERP system}

Data obtained from the results of the integration of the web service server will then be analyzed so as to produce information in accordance with the purpose of the ERP system. The ERP system built is a web-based information system that will display monthly sales reports, best-selling products, most customers, and other ERP functions such as sales data management and reporting by business owners. 


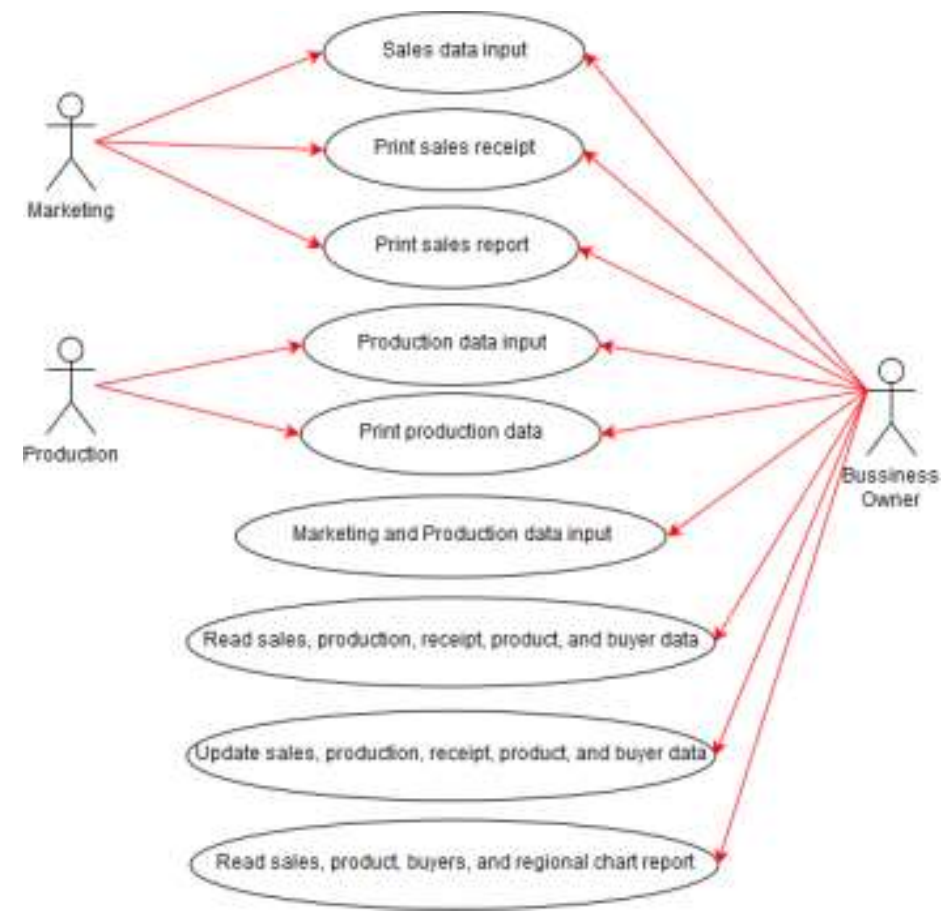

Figure 6. ERP system use case diagram

Figure 5 shows use case diagram for each actor involved in the business process of selling pens, production, invoice, goods, and customers in the Pari Fish Leather SMEs. There are 3 actors involved in this system. Broadly speaking, it can be explained that, the marketing and manufacturing department functions to provide sales and production data to the 3rd actor, namely the business owner, so that the owner can carry out data management and monitor business development through graph info.

\section{Results and Discussion}

The results achieved in this design are ERP systems that are integrated with marketing and manufacturing modules using web service technology. From that integrated system, the Pari Fish Leather SMEs will now have a developed business process that can ensure integrated data between the actors of the system and help them in decision making in order to optimize the use of limited resource of pari fish leather.

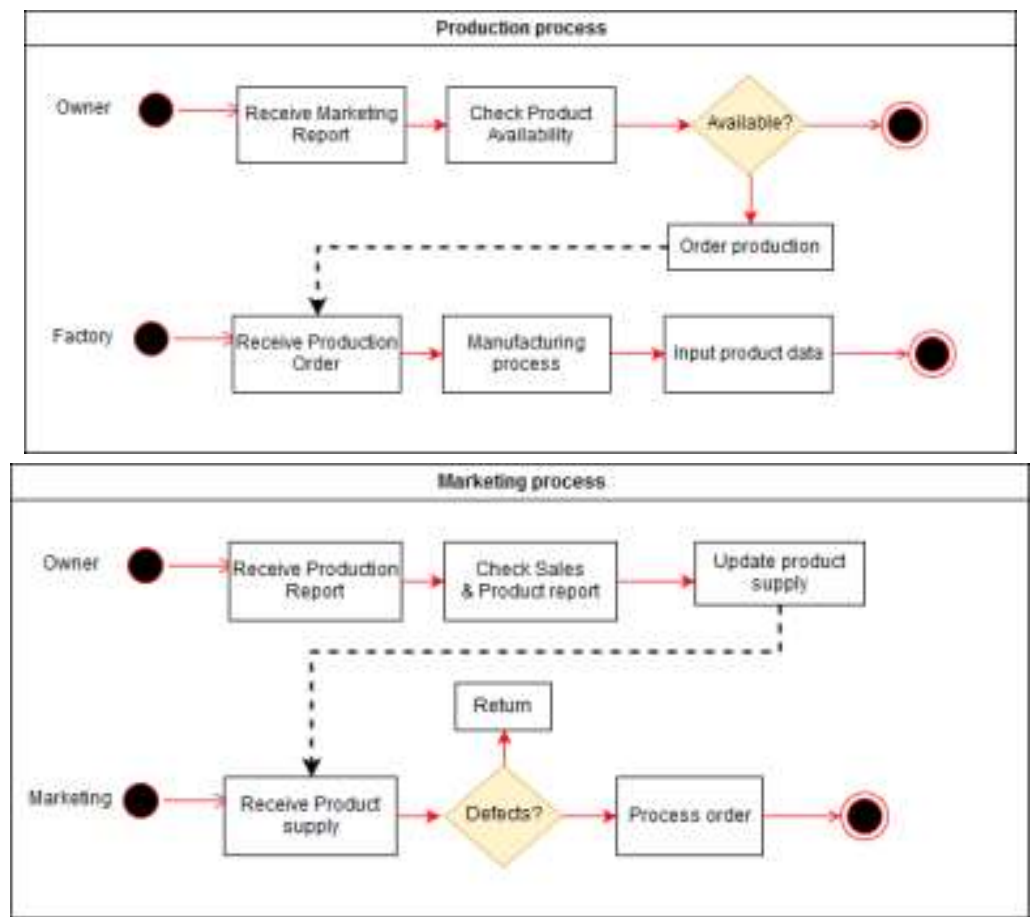

Figure 7. Developed business process from integrated ERP system 
The integrated system modules each have an interface that is used by the marketing department and manufacturers to run their respective business processes.

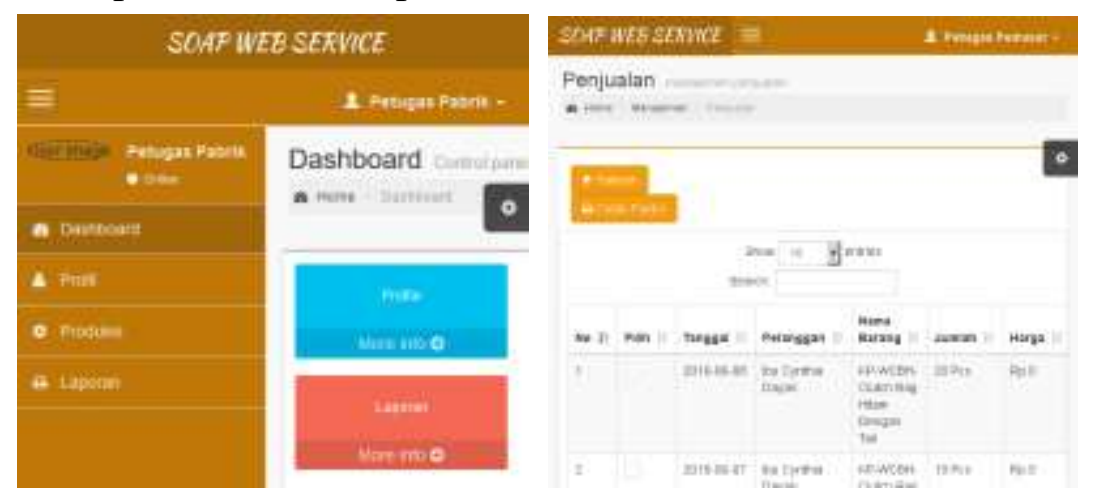

Figure 5. The manufacturing and marketing module as a SOAP client

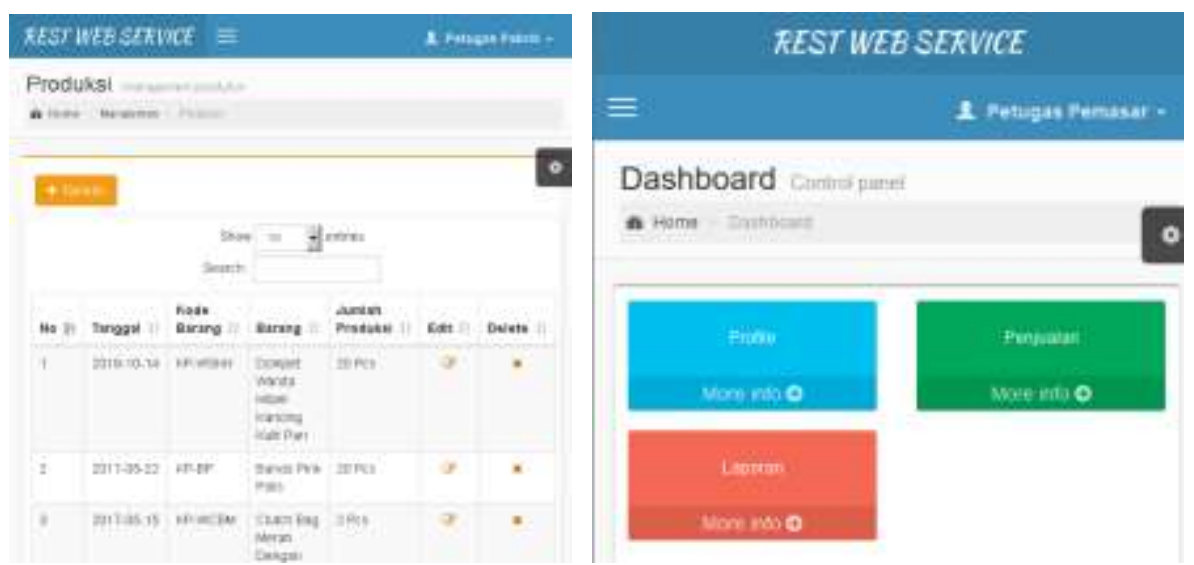

Figure 6. The manufacturing and marketing module as a REST client

The data integration model uses the SOAP and REST web service methods. Integration is carried out on each SOAP and REST web service server with the main server so that the ERP system can process marketing and manufacturer data.

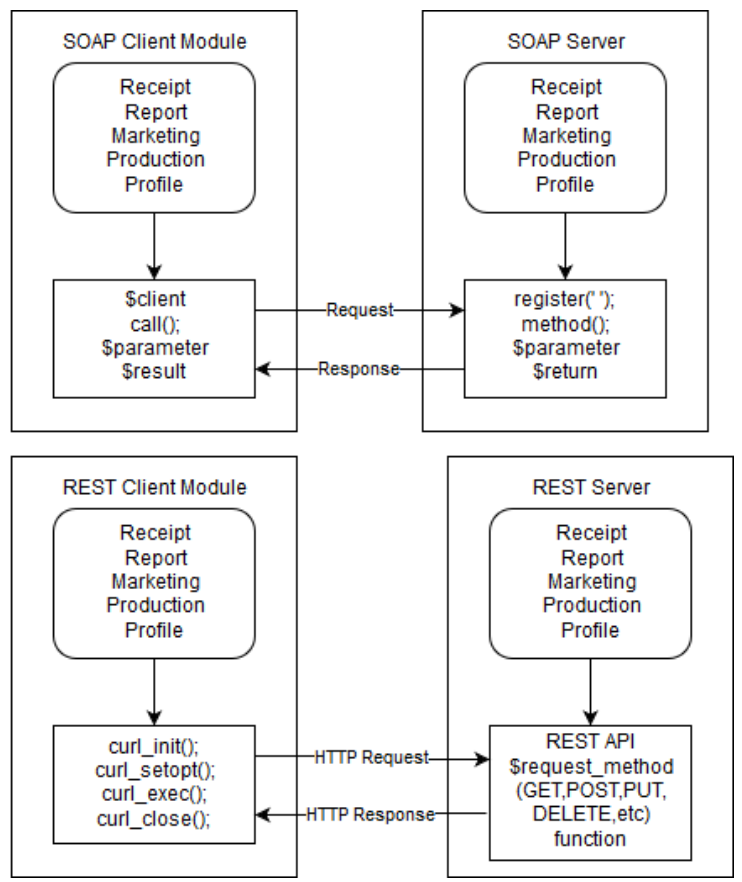

Figure 7. Module integration of SOAP and REST method 
The results of processing the data can be seen in the data graph on the dashboard's main page.

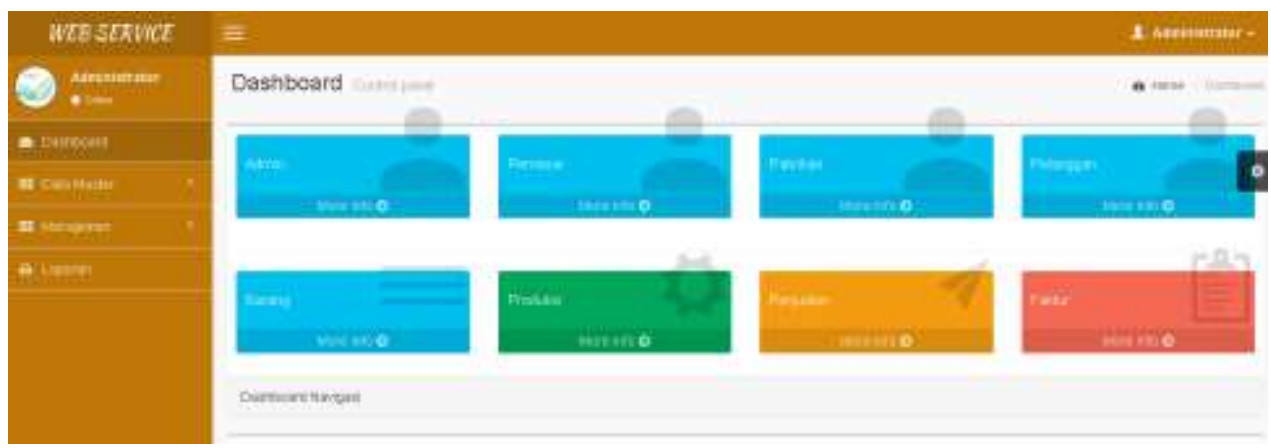

Figure 8. Display of the dashboard's main page (monitoring system) for business owner

\subsection{Sales Report Function}

This function displays the results of analysis of sales data in the form of a line graph that shows the level of the number of sales in a certain period of time based on the results of integration data contained in ERP information systems.

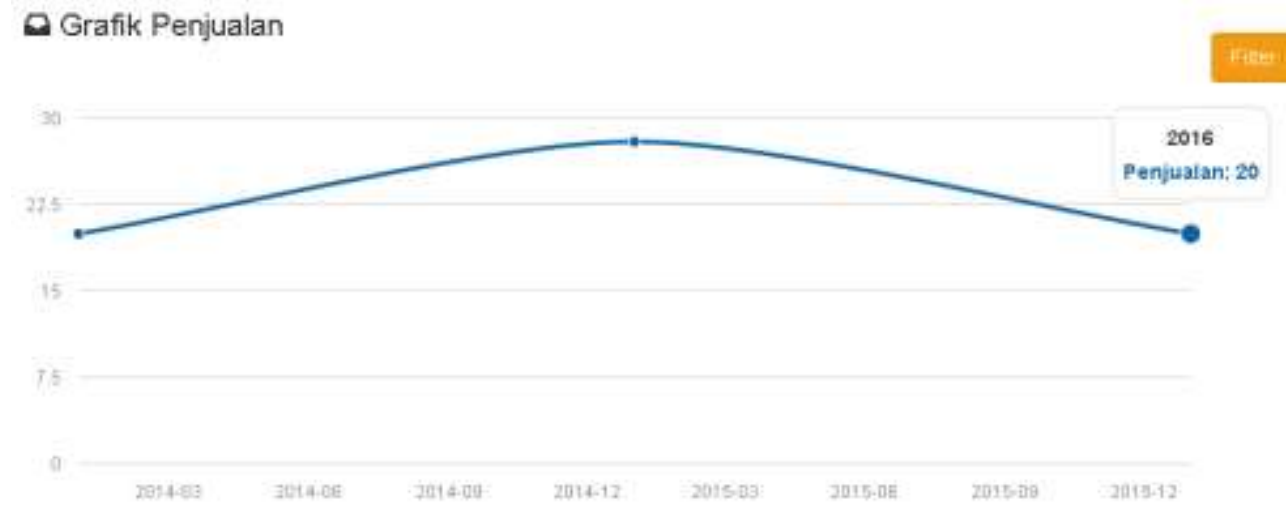

Figure 9. Graph of sales in the ERP monitoring system of marketing and manufacturers

The graph in figure 9 shows the level of sales from sales data in the time period specified by the user. This information shows the sales graph function that can help users in this case the business owner to be able to monitor the sales level of goods products in Pari Fish Leather SMEs as a reference in making business decisions.

\subsection{Product Report Function}

Product reports are made to display the results of the analysis of the number of sales of each item at a certain time according to the user's request. The analysis results are displayed in the form of a beam graph that shows the level of sales of each product on the same day, month, or year according to the user's request. 


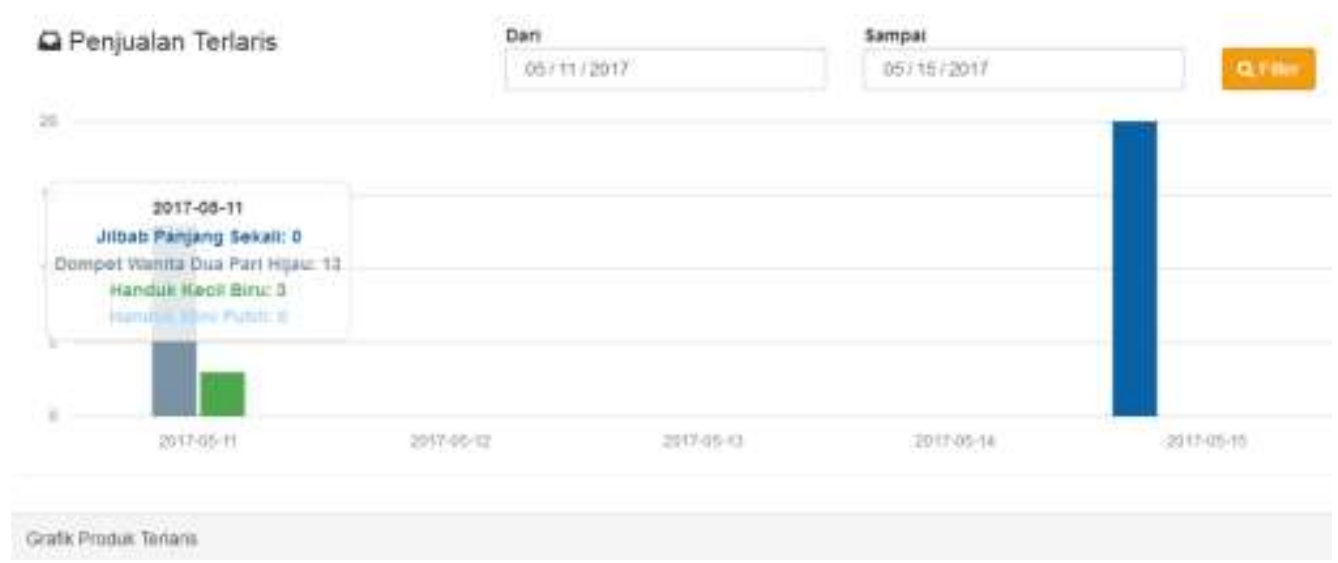

Figure 10. Graph of products in the ERP monitoring system of marketing and manufacturers

The graph in figure 10 shows the sales level of each item at a certain time range. Information from the graph can help business owners to monitor the level of sales of goods and their types (colors, shapes, etc.) for the needs of the amount of production in parts of the manufacturer that are in accordance with consumer behavior.

\subsection{Buyer Report Function}

The function of this report is to display the results of buyer data analysis based on the number and level of purchase of each item in graphical form.

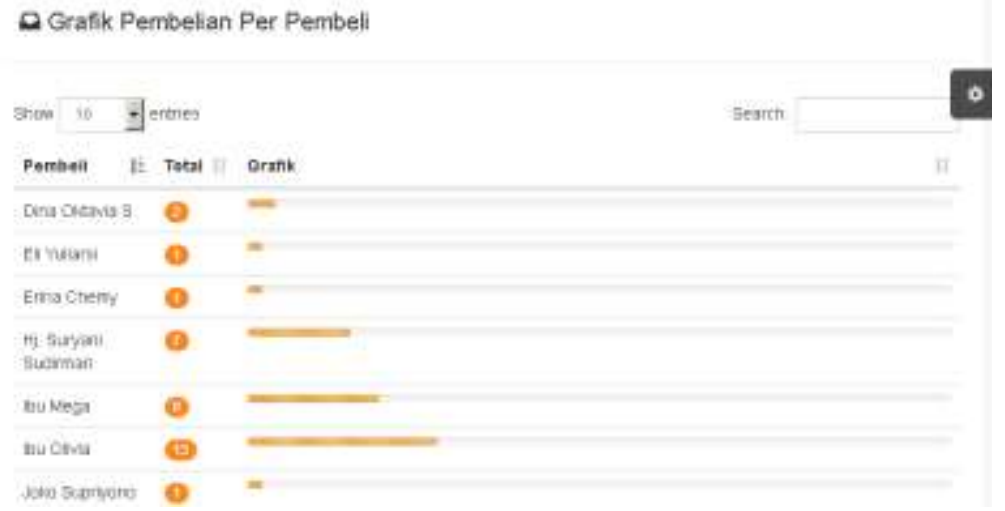

Figure 11. Buyer chart on ERP monitoring system from marketing and manufacturers

The graph in figure 11 shows the level and amount of purchases for each buyer that can help business owners to carry out ERP functions with more focus on each consumer according to their contribution to the level of product sales, in order to maintain buyer loyalty.

\subsection{Regional Buyers Report}

The last function contained in ERP information systems is regional reports. This function will display the results of data analysis in a graph that shows the level and amount of purchases based on the area of origin of the buyer. 


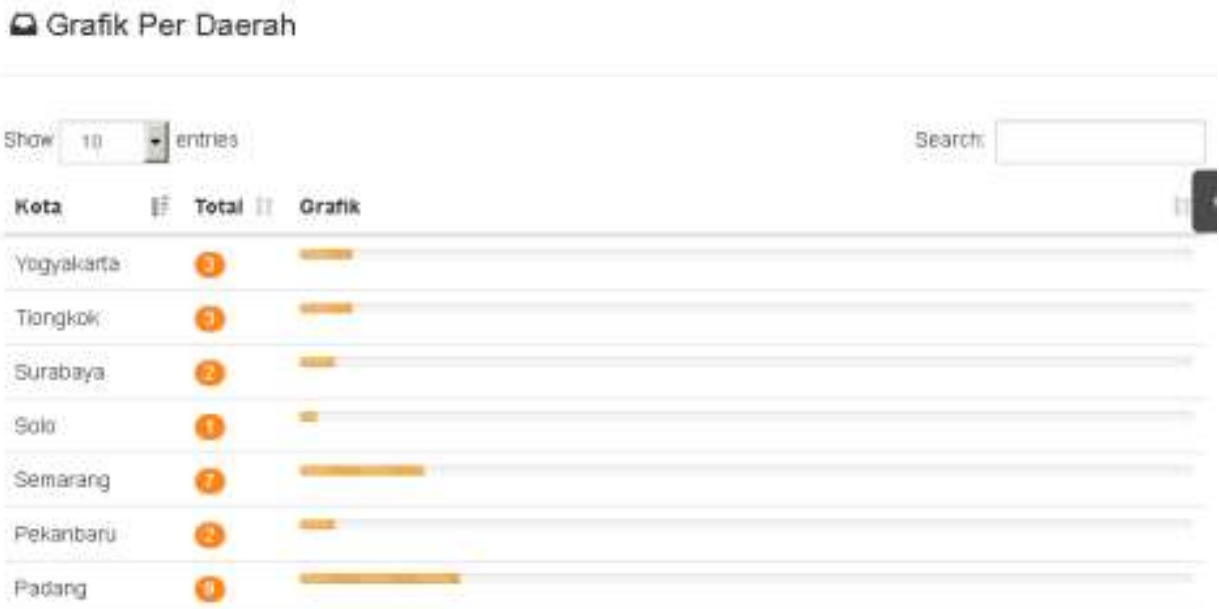

Figure 12. Graph of the origin of the ERP monitoring system of marketing and manufacturers

The graph in figure 12 shows the level and amount of sales of goods in the area of origin of the buyer, thus helping the business owner to be able to adjust the level of production in a particular area according to the level of sales in order to serve the needs of consumers in the area. This information can also be used to help increase sales in areas with sales that are still low compared to other regions.

\section{Conclusion and Future Research}

From the results of research and discussion of ERP system integration for Pari Leather SMEs, it can be concluded that:

1. Pari Fish Leather SMEs ERP System uses the SOAP and REST web service methods on sales data from the marketing department, and product data from the manufacturer's parts.

2. From traditional business process, data integration with web service technology resulting in developed business process that collaborate actors in ERP information system.

3. Data from integration results are analyzed to provide information in the form of graphic information to business owners who can assist in making decisions to improve customer service and the effectiveness of using raw materials.

4. ERP information systems allow business owners to carry out data management and faster decision-making to every business process in Pari Fish Leather SMEs.

The suggestions for future research are as follows:

1. There needs to be a comparison and evaluation of the performance from integration of the SOAP and REST methods to find out the advantages and disadvantages of each.

2. The business process developed by data integration can have more possibility I order to expand business coverage, so there is needs for further identification in this field of research.

3. Designing an integrated system that allows flexible web services and can adapt to changes in the business processes of different collaborative company.

\section{References}

[1] Bahrami, M, Ghorbani, M, Arabzad, S, \& Mohammad 2012, 'Information Technology (IT) as An Improvement Tool For Customer Relationship Management (CRM)', Procedia - Social and Behavioral Sciences, Vol. 41, pp. $59-64$.

[2] T. Nguyen, J, Sherif, M, Newby 2007, 'Strategies for successful CRM implementation', Information Management \& Computer Security, Vol. 15, pp. 102-11.

[3] Yogeswara, W.K, Wisnubhadra, I, \& Mudjihartono, P 2013, 'Analisis dan Rancang Bangun Sistem 
Informasi Hotel Terintegrasi yang Selaras dengan Rencana Strategis Teknologi Informasi', Proceeding Seminar Nasional Teknologi Informasi dan Komunikasi 2013 Yogyakarta, pp. 80-86.

[4] Motiwalla, L. V, Thompson, J 2009, 'Enterprise Systems for Management', Pearson Education, Inc, New Jersey, USA.

[5] Sinha, R, Khatkar, M, Gupta, S, Chand 2014, 'Design \& Development of a REST based Web Service Platform for Applications Integration on Cloud', International Journal of Innovative Science, Engineering \& Technology, Vol.1, pp. 385-389.

[6] Shah, J. R, Murtaza, Mirza B 2005, 'Effective Customer Relationship Management through Web Services', Journal of Computer Information Systems, Vol.46, Page 98.

[7] Nurcahyo, Yusuf, E, Santoso, P.B, \& Soenoko, R 2012, 'Penerapan Enterprise Resource Planning (ERP) Adempiere pada Perusahaan PT Global Agrotek Nusantara (GAN)', BISTEK Jurnal Bisnis dan Teknologi, Vol. 20 No.1, pp. 76-86.

[8] Utomo, W. H 2016, 'Pemrograman Web Services dan SOA dengan NetBeans', Penerbit Andi, Yogyakarta.

[9] Yogiswara, dkk 2014, 'Kinerja Web Service pada Proses Integrasi Data', Jurnal EECCIS, Vol.1, pp. 73-78.

[10]Chang, S. F, dkk 2014, 'Measuring the Service Quality of E-Commerce and Competitive Strategies', International Journal of Web Services Research (IJWSR), Vol. 11, Issue 3, pp. 96-115.

[11]Azevedo, P. S, dkk 2014, 'Application Integration: Enterprise Resource Planning (ERP) systems In the hospitality industry’, Procedia Technology, Vol.16, pp. 52-58.

[12]Cruz-Cunha, M. M, Varajao, Joao 2010, 'Enterprise Information Systems Design, Implementation and Management:Organizational Applications', Business Science Reference, Hershey, New York.

[13] Schneider, Benjamin. Bowen, David. E 2009. 'Modeling the Human Side of Service Delivery', Service Science, Vol.1, Issue 3, pp. 154-168.

[14]Daniel, Florian. Pernici, Barbara 2008. 'Chapter XII Web Service Orchestration and Choreography: Enabling Business Processes on the Web', IGI Global, Italy. 